\title{
Age of onset of episodic and chronic cluster headache - a review of a large case series from a single headache centre
}

\author{
Gian Camillo Manzoni ${ }^{1 *}$, Arens Taga ${ }^{1}$, Marco Russo ${ }^{2}$ and Paola Torelli ${ }^{1}$
}

\begin{abstract}
Background: In the largest case series of cluster headache $(\mathrm{CH})$ published in the literature, age of onset varies between 29.6 and 31.6 years. Differences in onset age based on gender and subtype diagnosis are reported, while there are only few data on patients with childhood and elderly onset. We therefore deemed it useful to review our own large case series of $\mathrm{CH}$ patients.

Methods: The age of onset of cluster headache was investigated in a consecutive case series of 808 patients (585 men and 223 women), including 686 (503 men and 183 women) with episodic cluster headache (ECH), 103 (66 men and 37 women) with chronic cluster headache (CCH), and 19 with an indeterminate form of $\mathrm{CH}$ (16 men and three women).

Results: The mean age of onset was $30.2 \pm 13.8$ years (30.1 \pm 13.0 in men and $30.4 \pm 15.7$ in women). The women with primary CCH had a mean onset age of $42.8 \pm 21.7$ years, while the women with secondary $\mathrm{CCH}$ did not differ much from those with ECH. Distribution of the study subjects by decades of onset age showed a peak in the third decade both in men and in women, but when only CCH patients were considered it displayed a more marked bimodal pattern in women (with peaks in the second and the sixth decade) than men (with peaks in the third and the fifth decade). The clear male predominance in cases with onset in the central age groups became attenuated in the extreme age groups. In patients with onset between $\leq 15$ years and $\geq 50$ years, the traditional male-to-female ratio was actually inverted in CCH.

Conclusions: Based on these epidemiological findings, it would be important to investigate the possible role, causative or protective, played by hormonal factors in $\mathrm{CH}$ pathogenesis.
\end{abstract}

\section{Background}

In the largest case series of cluster headache $(\mathrm{CH})$ published in the literature, age of onset varies between 29.6 [1], 30.7 [2] and 31.6 years [3], namely between 29.7 [4] and 31.3 years [5] in men and between 29.4 [5] and 32.8 years in women [3]. Moreover, as already reported by Horton in 1964, chronic $\mathrm{CH}(\mathrm{CCH})$ is likely to occur at a later age [6]; indeed, all subsequent literature indicates $[1-3,7,8]$ a mean age of $\mathrm{CCH}$ onset varying between 33.4 [1] and 39.0 years [7] versus between 28.4 [7] and 30.5 years [3] for episodic $\mathrm{CH}(\mathrm{ECH})$.

As early as 1980, Kudrow reported that "peculiar to the female distribution, an increased frequency occurred between the ages of fifty and sixty years" [1]; later

\footnotetext{
*Correspondence: giancamillo.manzoni@unipr.it

${ }^{1}$ Centro Cefalee, Dipartimento di Emergenza-Urgenza e Area Medica Generale e Specialistica, Azienda Ospedaliero-Universitaria di Parma, Padiglione Barbieri $3^{\circ}$ piano, Via Gramsci 14, 43126 Parma, Italy Full list of author information is available at the end of the article
}

studies showed this to be true especially for women with $\mathrm{CCH}[2,4]$.

While $\mathrm{CH}$ onset in the elderly is not frequent but possible [2], in children and adolescents it is so rare that the few studies published in the literature on $\mathrm{CH}$ in these age groups concern very small numbers of patients [9-11].

Recently, Zidverc-Trajcovic et al. [12] have considered as early onset a $\mathrm{CH}$ onset age under 20 years, common onset between 20 and 40 years, and late onset over 40 years. However, in nearly half of $\mathrm{CH}$ patients the disease sets in before 20 or after 40; so, the age limits suggested by these authors do not seem adequate to delineate atypical onset ages for $\mathrm{CH}$. In order to exactly define them, a different distribution, based not on decades but on more restricted age groups, would be needed, which obviously requires very large cases series.

We therefore deemed it useful to review our own large case series of $\mathrm{CH}$ patients seen at the Parma Headache 
Centre in order to: (a) define onset age distribution by age groups; (b) evaluate possible differences in onset age based on gender and subtype diagnosis (episodic or chronic $\mathrm{CH}$ ); (c) determine the number of cases and distribution by gender and subtype diagnosis among patients with childhood and elderly onset; and (d) detect the age limits below and above which onset ages can be considered "atypical".

\section{Methods}

We considered all consecutive patients referred to the Parma Headache Centre between November 1975 and November 2015 who were affected by $\mathrm{CH}$ and diagnosed by our team of trained neurologists.

$\mathrm{CH}$ diagnosis had originally been established according to the 1962 Ad Hoc Committee on Classification of Headache [13] for the pre-1988 referrals and on the International Headache Society (IHS) classifications for post-1988 referrals [14-16]. All patients were exhaustively evaluated in face-toface interviews to obtain valid and detailed information; a neurological examination was performed and secondary headache diagnoses were excluded.

We then reviewed our patients' clinical records - which have not changed since 1975 and have ever since reported all clinical information required for diagnosis - and revised all $\mathrm{CH}$ diagnoses prior to 2013 applying the current criteria of the beta version of the 3rd edition of the International Classification of Headache Disorders (ICHD-3 beta) [16]. During this diagnostic revision, 85 patients were excluded from our case series for a variety of reasons: age of onset not known (32 patients), misdiagnosis with paroxysmal hemicrania for pre-1988 cases (28 patients), and lack of sufficient clinical information for a certain diagnosis of $\mathrm{CH}$ (25 patients).

The overall sample comprised $808 \mathrm{CH}$ patients (585 men and 223 women).

For $\mathrm{CCH}$ cases, we considered separately those with primary $\mathrm{CCH}$, i.e. chronic ab initio, and those with secondary $\mathrm{CCH}$, i.e. evolving from $\mathrm{ECH}[14,15]$; this distinction is not present in the current IHS classification [16], but we think it could be of clinical interest.

In 19 cases, we could not define a clear temporal pattern, i.e. episodic or chronic, because some of them seemed to cross each other, while others were referred to our Headache Centre during their first cluster bout and were "lost" during the subsequent follow-up.

For the determination of $\mathrm{CH}$ age onset, we therefore considered only those cases in which this information could be established with certainty; comparisons by gender and subtype diagnosis were performed.

In our analysis, atypical onset ages were defined by convention as those under or over which no more than $10 \%$ of cases are represented.

Informed consent was obtained from all subjects who participated in our study.

\section{Statistical analysis}

Student's t-tests for independent samples were used for comparisons between means. The collected data were analyzed using SPSS, version 20.0 for Windows. We calculated twotailed $\mathrm{p}$-values and set statistical significance at $\mathrm{p} \leq 0.05$.

\section{Results}

Our case series comprised 808 patients with $\mathrm{CH}$, including 585 men (72.4) and 223 women (27.6 \%). The male-tofemale (M:F) ratio was 2.6:1. A total of 686 patients (503 men and 183 women) had ECH, 103 (66 men and 37 women) had $\mathrm{CCH}$, and 19 had an indeterminate form of $\mathrm{CH}$. The M:F ratio was 2.7:1 in ECH patients and 1.8:1 in $\mathrm{CCH}$ patients.

The mean age of onset in our $808 \mathrm{CH}$ patients was $30.2 \pm 13.8$ years (range $1-75$ ), namely $30.1 \pm 13.0$ years in the 585 men (range $1-75$ ) and $30.4 \pm 15.7$ years (range $5-74)$ in the 223 women.

The mean onset ages of patients with $\mathrm{ECH}$ and $\mathrm{CCH}$, both male and female, are reported in Table 1. Female patients were decisive in making the differences in onset ages of $\mathrm{ECH}$ and $\mathrm{CCH}$ reach statistical significance $(p=0.004)$ (Table 1 ). The primary form of $\mathrm{CCH}$ had a later onset than the secondary form, especially in women (Table 1).

Onset age distribution by decades peaked in the third decade for both sexes and showed a high number of onsets in the second and the fourth decade among men and in the second and the fifth decade among women (Fig. 1). From the sixth decade onward, the number of onsets decreased considerably in men and much less so in women; so, the M:F ratio was reduced to $1.4: 1$ for the 90 cases with onset at $\geq 50$ years and to $1: 1$ for the 34 cases with onset at $\geq 60$ years (Fig. 1 ).

When only $\mathrm{CCH}$ cases of both sexes were considered, onset still peaked in the third decade (30 out of 103 cases), but a bimodal pattern emerged with a second peak in the fifth and the sixth decade (30 cases overall). Considering the two sexes separately, the two peaks were in the third and the fifth decade among men (25 and 13 cases out of 66, respectively), and in the second and the sixth decade among women (eight cases each out of 37) (Fig. 2). ECH

Table 1 Age of onset of cluster headache by sex and subtypes

\begin{tabular}{|c|c|c|c|c|c|c|c|}
\hline & & \multicolumn{3}{|c|}{ Mean (yrs) } & \multicolumn{3}{|c|}{ SD (yrs) } \\
\hline & & Males & Females & $\overline{\text { Total }}$ & Males & Females & Total \\
\hline Episodic & & 29.7 & $29.0(1)$ & 29.5 & 12.9 & 14.2 & 13.3 \\
\hline \multicolumn{8}{|l|}{ Chronic } \\
\hline & All chronic & 32.0 & $37.2(1)$ & 33.9 & 13.4 & 21.1 & 16.6 \\
\hline & Primary & 35.7 & 42.8 & 38.5 & 16.3 & 21.7 & 18.8 \\
\hline & Secondary & 28.9 & 30.8 & 29.5 & 9.5 & 18.9 & 13.1 \\
\hline Total & & 30.1 & 30.4 & 30.2 & 13.0 & 15.7 & 13.8 \\
\hline
\end{tabular}

(1) Student's test: episodic cluster headache vs chronic cluster headache among females $p=0.004$ 


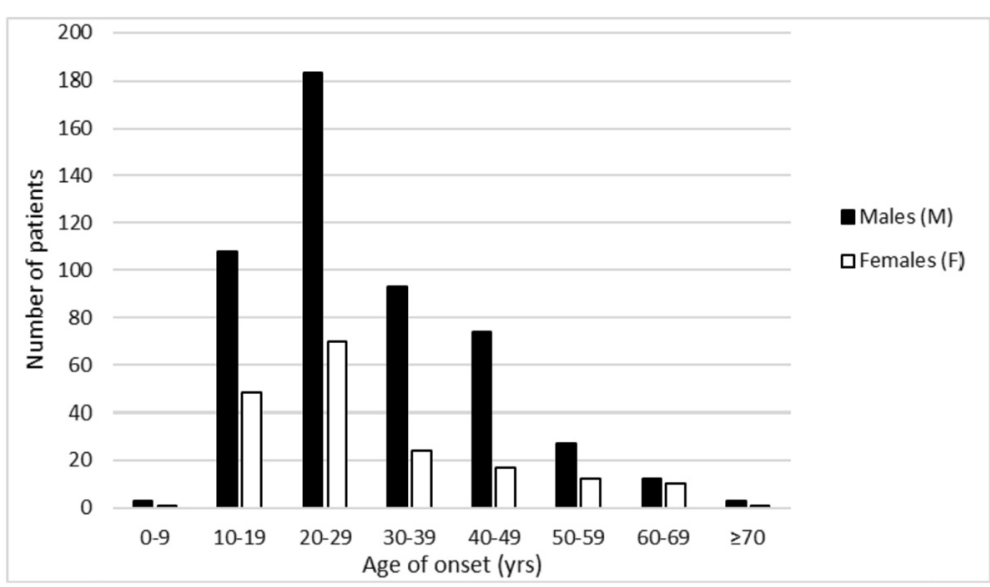

Fig. 1 Age of onset by decades and gender (808 cluster headache cases)

did not show the same bimodal pattern as $\mathrm{CCH}$, with a single peak in the third decade for both sexes.

Onset age distribution showed that there were few cases with onset in the first decade and from the sixth decade onward; by contrast, there were several cases with onset in the second decade (175, i.e. 119 men and 56 women) and also in the fifth decade (110, i.e. 89 men and 21 women).

As our case series was large enough to allow it, in order to have a more precise idea of onset age in relation to a subject's age we carried out a distribution analysis by five-year age groups, which in our opinion was more adequate than age distribution by decades to better detect the likelihood of childhood and elderly onset.

We were therefore able to find that the high number of cases seen in the second decade was basically the result of onset in the 15-19 age group (130 of the 175 cases of the second decade), while in the 10-14 age group there was a sharp reduction (only 45 cases) (Table 2). We found a similar, though less marked
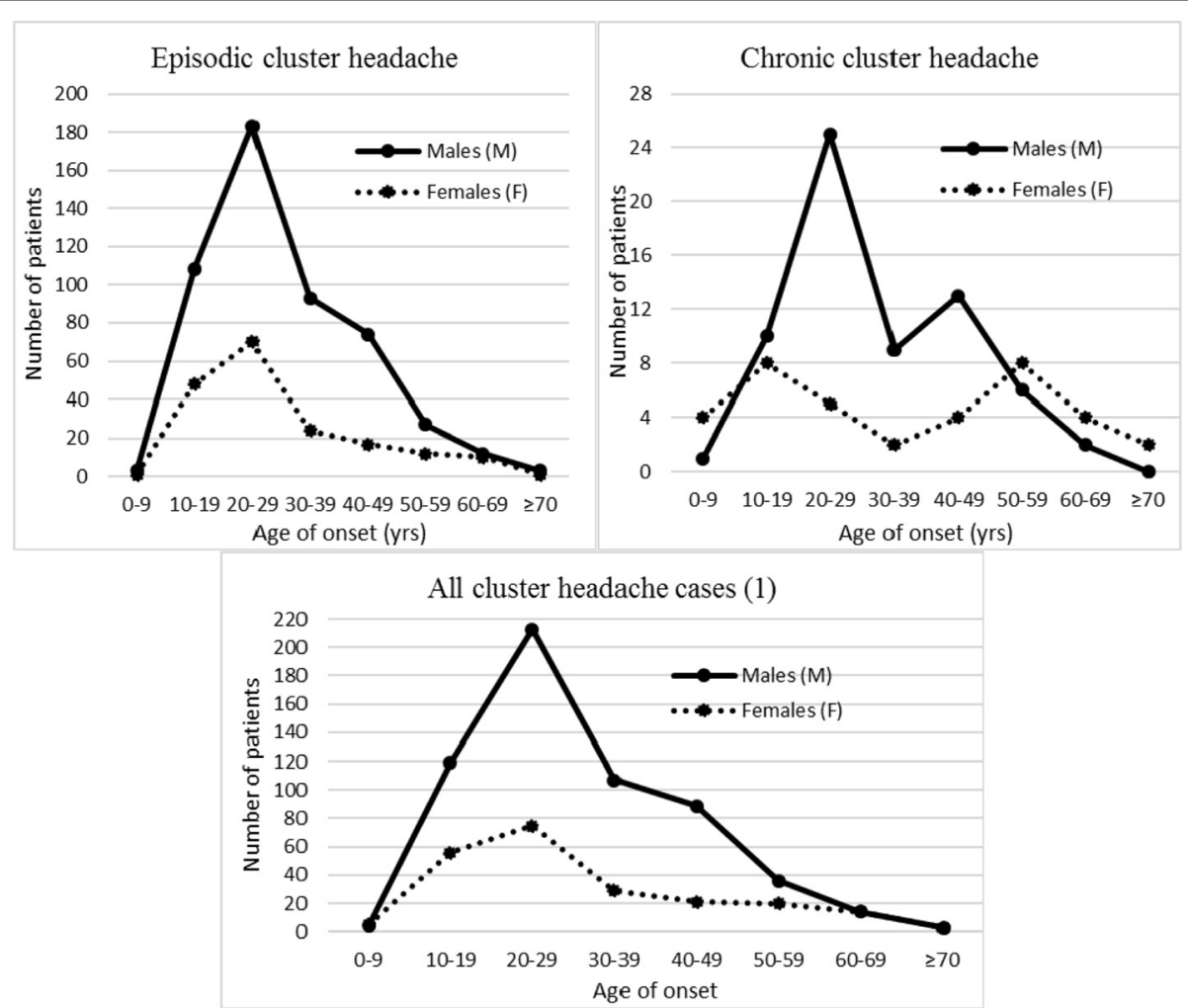

Fig. 2 Cluster headache age of onset by gender and subtype 
Table 2 Cluster headache $(\mathrm{CH})$ age of onset by age groups, gender and subtypes

\begin{tabular}{|c|c|c|c|c|c|c|c|c|c|}
\hline \multirow[b]{2}{*}{ Age of onset (yrs) } & \multicolumn{3}{|c|}{ Episodic CH } & \multicolumn{3}{|c|}{ Chronic CH } & \multicolumn{3}{|c|}{ All CH cases (1) } \\
\hline & Males & Females & $M: F$ & Males & Females & $M: F$ & Males & Females & $M: F$ \\
\hline $0-4$ & 1 & 0 & - & 0 & 0 & - & 1 & 0 & - \\
\hline $5-9$ & 2 & 1 & 2.0 & 1 & 4 & 0.3 & 3 & 5 & 0.6 \\
\hline $10-14$ & 26 & 15 & 1.7 & 2 & 2 & 1.0 & 28 & 17 & 1.6 \\
\hline $15-19$ & 82 & 33 & 2.5 & 8 & 6 & 1.3 & 91 & 39 & 2.3 \\
\hline $20-24$ & 106 & 47 & 2.3 & 11 & 0 & - & 122 & 47 & 2.6 \\
\hline $25-29$ & 77 & 23 & 3.3 & 14 & 5 & 2.8 & 91 & 28 & 3.3 \\
\hline $30-34$ & 56 & 12 & 4.7 & 4 & 0 & - & 62 & 15 & 4.1 \\
\hline $35-39$ & 37 & 12 & 3.1 & 5 & 2 & 2.5 & 45 & 14 & 3.2 \\
\hline $40-44$ & 49 & 12 & 4.1 & 7 & 2 & 3.5 & 56 & 14 & 4.0 \\
\hline $45-49$ & 25 & 5 & 5.0 & 6 & 2 & 3.0 & 33 & 7 & 4.7 \\
\hline $50-54$ & 17 & 7 & 2.4 & 5 & 5 & 1.0 & 23 & 12 & 1.9 \\
\hline $55-59$ & 10 & 5 & 2.0 & 1 & 3 & 0.3 & 13 & 8 & 1.6 \\
\hline $60-64$ & 6 & 9 & 0.7 & 1 & 2 & 0.5 & 7 & 11 & 0.6 \\
\hline $65-69$ & 6 & 1 & 6.0 & 1 & 2 & 0.5 & 7 & 3 & 2.3 \\
\hline $70-74$ & 2 & 1 & 2.0 & 0 & 2 & - & 2 & 3 & 0.7 \\
\hline$\geq 75$ & 1 & 0 & - & 0 & 0 & - & 1 & 0 & - \\
\hline Total & 503 & 183 & 2.7 & 66 & 37 & 1.8 & 585 & 223 & 2.6 \\
\hline
\end{tabular}

(1) Among all cluster headache cases, 19 cases had an indeterminate temporal pattern

pattern, in the two five-year periods of the fifth decade (70 out of 110 cases in the $40-44$ age group and only 40 cases in the 45-49 age group) (Table 2).

Moreover, while the remarkable reduction in the number of patients with onset in the 10-14 age group became progressively more accentuated in the previous five-year periods, the decrease found in the 45-49 age group was less marked and was not followed by a similarly progressive and accentuated reduction in the next five-year periods, especially in women (Table 2 and Fig. 3).

$\mathrm{CH}$ set in at $\leq 14$ years in 54 of our 808 patients, or $6.7 \%$ (32/585 men, $5.5 \%$; 22/223 women, $9.9 \%)$, at $\geq$
50 years in 90 , or $11.1 \%(53 / 585,9.1 \%$; 37/223, $16.6 \%)$, and at $\geq 55$ years in 55 , or $6.8 \%(30 / 585,5.1 \% ; 25 / 223$, $11.2 \%)$ (Table 2).

The M:F ratio was $1.5: 1$ in patients with onset at $\leq$ 14 years, 1.4:1 in those with onset at $\geq 50$ years, and 1.2:1 in those with onset at $\geq 55$ years.

However, if $\mathrm{ECH}$ and $\mathrm{CCH}$ were considered separately, women were more numerous than men in these onset age groups of $\mathrm{CCH}$; indeed, the M:F ratio in patients with onset at $\leq 14$ years was 1.8:1 in $\mathrm{ECH}$ and 0.5:1 in $\mathrm{CCH}$; in patients with onset at $\geq 50$ years it was $1.8: 1$ in $\mathrm{ECH}$ and 0.6:1 in $\mathrm{CCH}$ (Table 2).

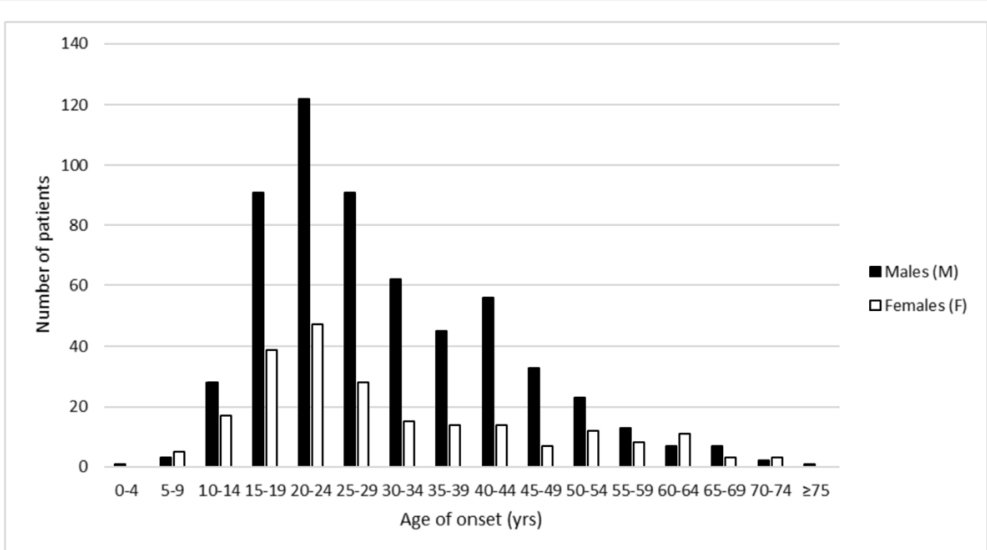

Fig. 3 Age of onset by five-year age groups and gender (808 cluster headache cases) 
When considering atypical onset age as previously defined, it appeared to differ in the two sexes: it varied between $\leq 15$ years $(52 / 585$ cases, $8.9 \%)$ and $\geq 50$ years $(53 / 585,9.1 \%)$ for $\mathrm{CH}$ males and between $\leq 14$ years (22/223 cased, 9.9) and $\geq 58$ years $(21 / 223,9.4 \%)$ for $\mathrm{CH}$ females (Table 3).

\section{Discussion and conclusions}

Confirming what has already been reported by several authors [1-8], the review of our case series of $\mathrm{CH}$ patients shows that the mean age of onset is around 30 years. If we consider $\mathrm{ECH}$ and $\mathrm{CCH}$ separately, we can see that the mean onset age is older ( $33.9 \pm 16.6$ years) in the latter, but this is only due to the figure ( $38.5 \pm 18.8$ years) for the $\mathrm{CCH}$ subtype that until the 2004 international headache classification [15] was called primary $\mathrm{CCH}$, i.e. chronic ab initio; by contrast, the onset age of secondary $\mathrm{CCH}$, i.e. $\mathrm{CH}$ that has become chronic only after several years with a periodic time pattern, is entirely comparable to that of
ECH $(29.5 \pm 13.1$ year and $29.5 \pm 13.3$ years $)$. In women, this difference is even more marked $(42.8 \pm 21.7$ years for primary $\mathrm{CCH}, 30.8 \pm 18.9$ years for secondary $\mathrm{CCH}$, and $29.0 \pm 14.2$ years for $\mathrm{ECH}$ ).

The analysis of onset age distribution by age groups confirms the presence of a peak in the third decade and of a bimodal pattern only in women with a further peak at a more advanced age $[1,2,4,7,17]$.

In addition to confirming some observations already reported in the literature about age of $\mathrm{CH}$ onset, with this study we were able to acquire new knowledge from our very large case series (808 patients). The only case series larger than ours was that of Rozen and Fishman in the US [17], which consisted of 1,134 patients; these, however, were recruited in the Internet and were not seen personally as were ours.

Our data show that the previously reported bimodal pattern of $\mathrm{CH}$ onset age in women can be observed only in $\mathrm{CCH}$, with two peaks in the second and the sixth

Table 3 Cluster headache age of onset divided by year ( $<20$ and $>45$ years) and gender

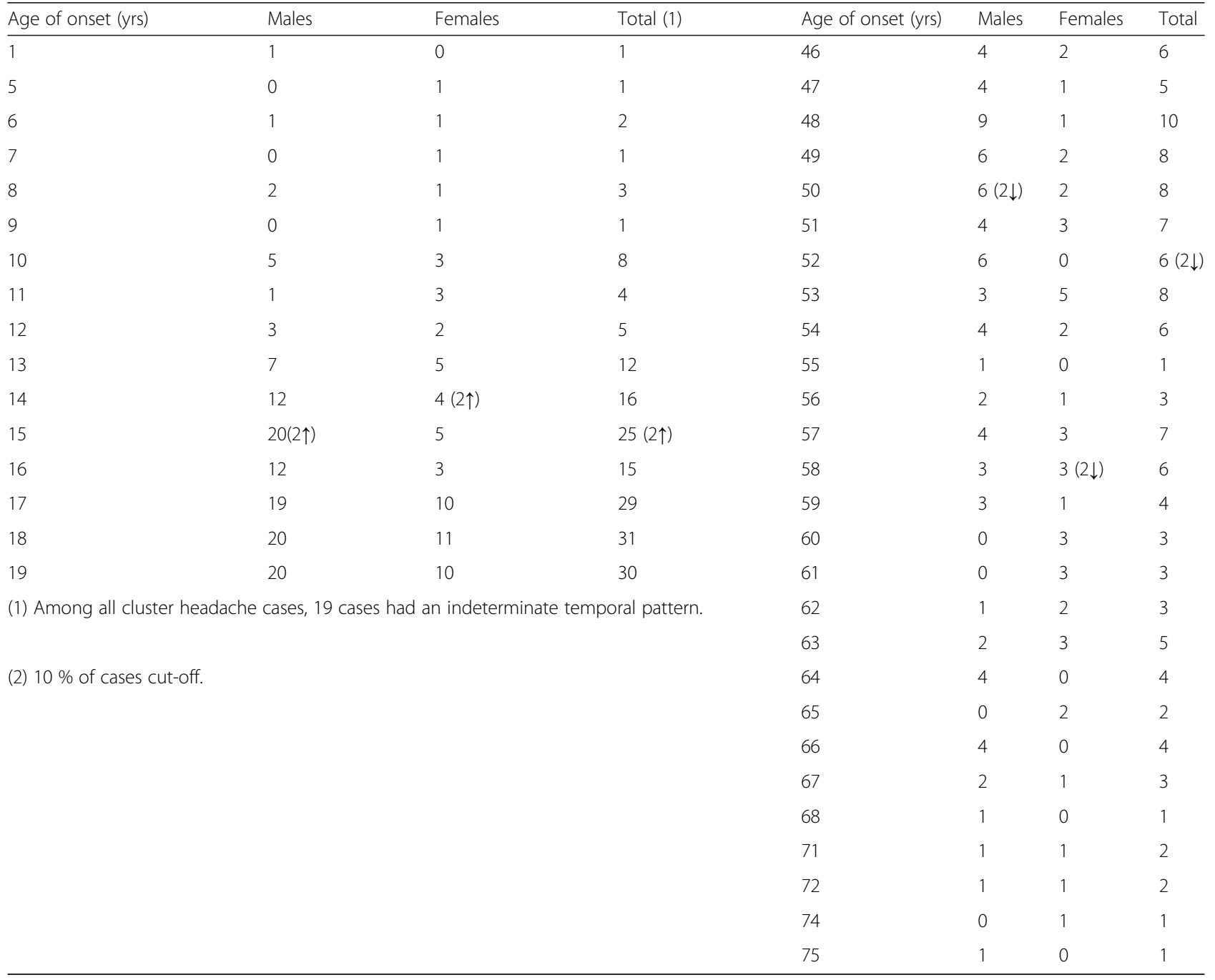


decade, respectively (Fig. 2). In $\mathrm{CCH}$ males too, there is a bimodal pattern, though less marked than in females, with a peak in the third decade and another one, less marked, in the fifth decade (Fig. 2).

Another very interesting finding that emerged from the review of our cases series is that the male predominance in $\mathrm{CH}$ is more marked in patients with onset in the more central age groups and tends to decrease in the extreme age groups. When considering $\mathrm{CCH}$ separately for the two sexes, we can even see that there is a female predominance both in cases with childhood onset and in cases with onset at $\geq 50$ years. These are mostly primary $\mathrm{CCH}$ cases.

The onset age distribution by five-year age groups, the attempt to detect "atypical" onset ages and the analysis of the M:F ratio trends in relation to the different onset ages enables interesting conclusions to be drawn about women with $\mathrm{CH}$. In particular, the likelihood that a woman may develop $\mathrm{CH}$ appears the same as, if not higher than for $\mathrm{CCH}$, that of a man in pre-adolescence and from age 50 onward. This finding could be a stimulus for further studies aimed at investigating the possible role - causative or maybe protective - played by hormonal factors in $\mathrm{CH}$ pathogenesis.

Our study has methodological strengths and limitations that need to be considered.

Among the former are: (1) the case series that we report is very large and includes patients with $\mathrm{CH}$ diagnosis according to the ICHD-3 beta criteria; (2) the diagnosis was made by face-to-face examination, and secondary causes were excluded; (3) all reported cases were personally seen by the author himself (GCM).

Among the latter are: (1) the breakdown of our case series by diagnosis, sex and age group has led to smallsized subgroups, especially the subgroup of $\mathrm{CCH}$ women; (2) for that reason, we were not able to perform a statistical analysis to determine the significance of certain findings, in particular the bimodal pattern of onset ages in $\mathrm{CCH}$ women and the relatively higher proportion of women than men with onset in the extreme age groups, especially for $\mathrm{CCH}$.

It would be interesting to check our findings against larger case series, particularly for $\mathrm{CCH}$ women.

\section{Competing interests}

The authors declare that they have no competing interests.

\begin{abstract}
Authors' contributions
GCM conceived of the study, performed data interpretation and drafted the manuscript. AT and MR were involved in acquisition of data; AT performed statistical analysis and helped to draft the manuscript. PT critically revised the manuscript and participated in the study conception and design. All authors read and approved the final manuscript.
\end{abstract}

\section{Author details}

${ }^{1}$ Centro Cefalee, Dipartimento di Emergenza-Urgenza e Area Medica Generale e Specialistica, Azienda Ospedaliero-Universitaria di Parma,
Padiglione Barbieri $3^{\circ}$ piano, Via Gramsci 14, 43126 Parma, Italy. ${ }^{2}$ Dipartimento di Medicina Clinica e Sperimentale, Università degli Studi di Parma, Parma, Italy.

Received: 17 January 2016 Accepted: 7 April 2016

Published online: 22 April 2016

\section{References}

1. Kudrow L (1980) Cluster headache. Mechanisms and management. Oxford University Press, New York

2. Manzoni GC, Maffezzoni M, Lambru G, Lana S, Latte L, Torelli P (2012) Lateonset cluster headache: some considerations about 73 cases. Neurol Sci 33(suppl1):S157-S159

3. Gaul C, Christmann N, Schröder D, Weber R, Shanib H, Diener HC, Holle D (2012) Differences in clinical characteristics and frequency of accompanying migraine features in episodic and chronic cluster headache. Cephalalgia 32:571-577

4. Ekbom K, Svensson DA, Träff H, Waldenlind E (2002) Age at onset and sex ratio in cluster headache: observations over three decades. Cephalalgia 22:94-100

5. Rozen TD, Niknam RM, Shechter AL, Young WB, Silberstein SD (2001) Cluster headache in women: clinical characteristics and comparison with cluster headache in men. J Neurol Neurosurg Psychiatry 70:613-617

6. Horton BT (1964) Histaminic cephalgia linked with respiratory infections. Headache 4:228-236

7. Manzoni GC, Terzano MG, Bono G, Micieli G, Martucci N, Nappi G (1983) Cluster headache - clinical findings in 180 patients. Cephalalgia 3:21-30

8. Bahra A, May A, Goadsby PJ (2002) Cluster headache. A prospective clinical study with diagnostic implications. Neurology 58:354-361

9. Majumdar A, Ahmed MAS, Benton S (2009) Cluster headache in children experience from a specialist headache clinic. Eur J Paediatr Neurol 13:524-529

10. Arruda MA, Bonamico L, Stella C, Bordini CA, Bigal ME (2011) Cluster headache in children and adolescents: ten years of follow-up in three pediatric cases. Cephalalgia 31:1409-1414

11. Mariani R, Capuano A, Torriero R, Tarantino S, Properzi E, Vigevano F, Valeriani M (2014) Cluster headache in childhood: case series from a pediatric headache center. J Child Neurol 29:62-65

12. Zidverc-Trajcovic J, Markovic K, Radojicic A, Podgorac A, Sternic N (2014) Cluster headache: is age of onset important for clinical presentation? Cephalalgia 34:664-670

13. Ad Hoc Committee on the Classification of Headache of the NIH (1962) JAMA 179.717-718.

14. Headache Classification Committee of the International Headache Society (1988) Classification and diagnostic criteria for headache disorders, cranial neuralgias and facial pain. Cephalalgia 8(suppl7):1-96

15. Headache Classification Subcommittee of the International Headache Society (2004) The international classification of headache disorders. Cephalalgia 24(suppl1):1-160

16. Headache Classification Subcommittee of the International Headache Society (2013) The international classification of headache disorders. Cephalalgia 33:629-808 (beta version)

17. Rozen TD, Fishman RS (2012) Cluster headache in the United States of America: demographics, clinical characteristics, triggers, suicidality, and personal burden. Headache 52:99-113

\section{Submit your manuscript to a SpringerOpen ${ }^{\mathcal{O}}$ journal and benefit from:}

- Convenient online submission

- Rigorous peer review

- Immediate publication on acceptance

- Open access: articles freely available online

- High visibility within the field

- Retaining the copyright to your article

Submit your next manuscript at springeropen.com 